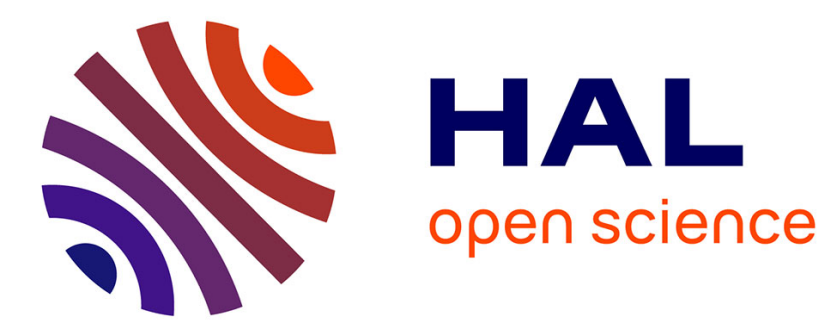

\title{
LATERAL TRANSPORT IN SUPERLATTICES
}

K. Hess

\section{To cite this version:}

K. Hess. LATERAL TRANSPORT IN SUPERLATTICES. Journal de Physique Colloques, 1981, 42 (C7), pp.C7-3-C7-17. 10.1051/jphyscol:1981701 . jpa-00221637

\section{HAL Id: jpa-00221637 https://hal.science/jpa-00221637}

Submitted on 1 Jan 1981

HAL is a multi-disciplinary open access archive for the deposit and dissemination of scientific research documents, whether they are published or not. The documents may come from teaching and research institutions in France or abroad, or from public or private research centers.
L'archive ouverte pluridisciplinaire HAL, est destinée au dépôt et à la diffusion de documents scientifiques de niveau recherche, publiés ou non, émanant des établissements d'enseignement et de recherche français ou étrangers, des laboratoires publics ou privés. 


\title{
LATERAL TRANSPORT IN SUPERLATTICES
}

\author{
$\mathrm{K}$. Hess
}

Department of Electrical Engineering and the Coordinated Science Laboratory University of Illinois at Urbana-Chompaign, Urbana, ILlinois 61801, U.S.A.

Résumé. - Des rêsultats théoriques et expérimentaux sur le transport latéral dans des hétérojonctions sont présentés. On a montré que le changement des conditions aux limites (périodiques ou non) donne naissance à une série de nouveaux effets prometteurs d'applications aux composants.

Ces effets seront présentés en insistant sur l'analogie entre 1'espace réel et 1'espace des $\vec{k}$.

Abstract. - Theoretical and experimental results are presented for lateral transport in layered heterojunction structures. It is shown that the variability of boundary conditions (periodic or nonperiodic) gives rise to a series of novel effects with high device potential. These effects will be presented stressing the real-space - $\vec{k}$-space analogy.

1. Introduction. - When I heard in $1977 \mathrm{C}$. Hilsum "s "Look Over The Shoulder" presented at the meeting in Denton [1], I did not realize that two years later $I$ would almost experience another direct proof of his last quotation from Hegel [2]. In 1979 Hadis Morkoç, Ben Streetman and myself were led to the idea of rea1-space transfer in superlattices [3], an effect which inter alia can be used to produce the real-space analogy of the Gunn effect in properly designed samples. We performed some preliminary calculations of this effect and submitted a manuscript [4] which was characterized by the first referee as unimportant, incomplete, and mostly wrong. We would have stopped the work on this project, if we had not obtained confirmation of our estimates by sophisticated Monte Carlo calculations performed by Glisson et al. [5] and calculations with the method of moments by Shichijo et a1. [6] as well as encouragement by discussions with J. Bardeen and H. Kroemer.

Meanwhile we also learned more about already well known variations of the real-space transfer effect. Among these variations are the electron emission from silicon into silicon dioxide which was discovered by Ning [7], the transfer of electrons to a floating gate in read only memories and the diffusion of hot electrons in graded gap semiconductors measured by Dargis et a1. [8]. Superlattices and sma11 quantum we11 heterostructure layers add many possibilities to these effects. In fact, a general correspondence of $\vec{k}$-space and real-space transport effects can be established. It is the purpose of this paper to describe the lateral transport in superstructures and to illustrate this $\vec{k}$-space-real-space correspondence on the basis of concrete examples. 
The major impetus to the interest in lateral transport in heterolayers came from the experimental verification of modulation doping by Dingle et a1. [9]. In sma11 heterolayers charge neutrality need not be conserved (in a first approximation) and donors and electrons can be separated over distances much larger than the effective Bohr radius. For example, if one dopes $\mathrm{Al}_{\mathrm{x}} \mathrm{Ga}_{1-\mathrm{x}} \mathrm{As}$ neighboring to GaAs the electrons move to the material with the lower band gap if the band edge discontinuity (a function of $x$ ) is sufficiently large. The electrons are then separated from their parent donors and experience much reduced impurity scattering. In 1979 we realized [3] that the inverse of this effect can happen in a high electric field parallel to the interface (not perpendicular, which was proposed by Esaki in a different context [10]). Electrons are accelerated by high fields and move up the (2 or 3 dimensiona1) continuum of states in the GaAs until they reach enough energy to transfer out. Then they are pulled back by the positively charged donors. It is clear that then the electrons experience strong impurity scattering and negative differential resistance can occur. These are the major ideas which will be presented in detail. In the second section I will describe the theory of the low field conductivity in heterolayers and the major differences of the scattering mechanisms to bulk material. Then the transfer mechanism and the general correspondence of $\vec{k}$-space-real-space effects will be discussed. This section is followed by experimental results confirming the real-space transfer effect and describing lateral transport in the ohmic, warm electron and hot electron range. Finally, in the conclusion I will present an outlook on future prospects in this area.

\section{Analytical Considerations}

\subsection{Conductivity in the Ohmic Range}

The idealized modulation-doped structure (e.g., $\left.A I_{x} \mathrm{Ga}_{1-\mathrm{x}} \mathrm{As}-\mathrm{GaAs}\right)$ is shown in Figure 1 a-c. Fig. la represents the conduction band edge for a negligible effect of the space charge. The distance $d_{i}$ is the spacing in the $\mathrm{Al}_{\mathrm{x}} \mathrm{Ga}{ }_{1-\mathrm{x}}$ As layer which is free of intentional doping. $z_{0}$ is the distance of the doping from the maximum of the square of the electron envelope wave-function for the lowest quantum state $E_{0}$ which is above the GaAs conduction band edge $E_{c}$. In $F i g$. Ib, I have made visible the effect of the space charge which causes some band bending. Note that $z_{0}$ is still about the same. In Fig. 1c the band bending is so strong that two quasitwo-dimensional layers form, one at each interface. $z_{0}$ is then much smaller. As we will see, the scattering rate for ionized impurity scattering is then strongly increased because it depends sensitively on the distance $z_{0}$. This distance causes the major reduction of impurity scattering; all the other effects such as twodimensionality have a smaller influence on the scattering rate and mobility.

A rigorous theory which explains the observed data has to include multisubband conduction and multisubband screening of remote and background impurities. It must also take into account interface and bulk polar optical phonons. Also, the continuum approximation for the built-in field (Fig. 1) is rather poor. In the following we use a simple model, which ignores these details. We can expect that 

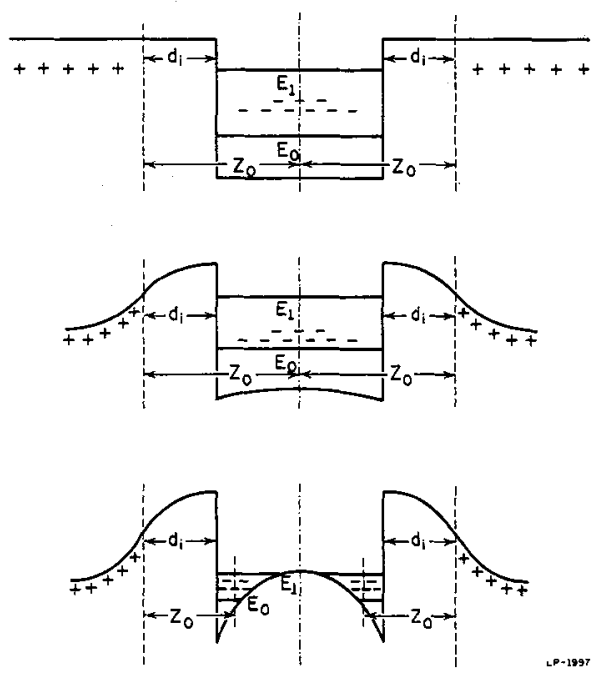

Fig. 1: Schematic diagram of the conduction band edge in modulation-doped GaAs-A1 ${ }_{x}{ }_{1-x}$ As layers including

(a) no band bending

(b) moderate band bending

(c) strong band bending

Note the change in $z_{o}$, which is the distance of the donors to the maximum electron charge density.

this model describes the transport in modulation-doped structures within a factor of two or so. Our model is purely two-dimensional with respect to the electrons. In reality, however, more than one subband will be populated and scattering channels (intersubband scattering) are opened. This can increase the scattering rate by about $1 / 3$ over the purely two-dimensional rate. A careful discussion of this effect was given by Price [11].

The electron distribution is approximated by a $\delta$-like sheet of electron charge located at $z=0$ where $z$ is the direction perpendicular to the layers. The donor impurities are homogeneously distributed at $z \geqslant z_{0}$. According to [12,13], the scattering rate is given by:

$$
\frac{1}{\tau}=\beta \int_{0}^{\pi} \exp \left(-4 k z_{0} \sin \theta\right) \sin \theta\{2 k \sin \theta+S\}^{-2} d \theta
$$

where

$$
\beta=e^{4}{ }^{*} N_{R}\left\{8 \pi \hbar^{3}\left(\varepsilon \varepsilon_{o}\right)^{2} k\right\}^{-1}
$$

Here $k$ is the absolute value of the electronic wave vector, $m$ the effective mass, $\mathrm{N}_{\mathrm{R}}$ the remote impurity density, $\varepsilon$ the relative dielectric constant of the semiconductor, $\varepsilon_{0}$ the dielectric constant of free space, $h$ is Planck's constant divided by $2 \pi$, and $S$ is the two-dimensional screening constant. In the limit of a high electron density, $n_{s}$, at the interface of the $\mathrm{Al}_{\mathrm{x}} \mathrm{Ga}_{1-\mathrm{x}} \mathrm{As} / \mathrm{GaAs}$ layers, $\mathrm{S}$ is a constant given by $S=2 / a_{B}$ where $a_{B}$ is the effective Bohr radius in the GaAs [12]. 
If the screening is strong, scattering occurs only for small values of $\theta\left(k_{0}>1\right)$ and $\sin \theta$ can be replaced by $\theta$ in the exponent of equation (1). Then

$$
\frac{1}{\tau} \simeq \frac{2 \beta}{s^{2}}\left[16 k^{2} z_{0}^{2}+1\right]^{-1}
$$

The result holds for background impurities also (i.e., $z_{0}=0$ ) and should allow an estimate of the influence of interface charges ( $\mathrm{kz}$ 。 very small). In most practical cases $k$ may be replaced by the Fermi wavevector $k_{F}$ in equations (1) and (2). This can be done because Fermi statistics is appropriate at low temperatures where impurity scattering is important. For one subband we have

$$
k_{F}=\sqrt{2 \pi n_{s}}
$$

Equations (1) - (4) give a rough description of impurity scattering in modulationdoped structures. If the true $z$-dependence of the subband envelope functions is taken into account, the formulae arising are much more involved. The essence of the theory, however, is reflected by equation (3) if $z_{0}$ is regarded as an adjustable parameter.

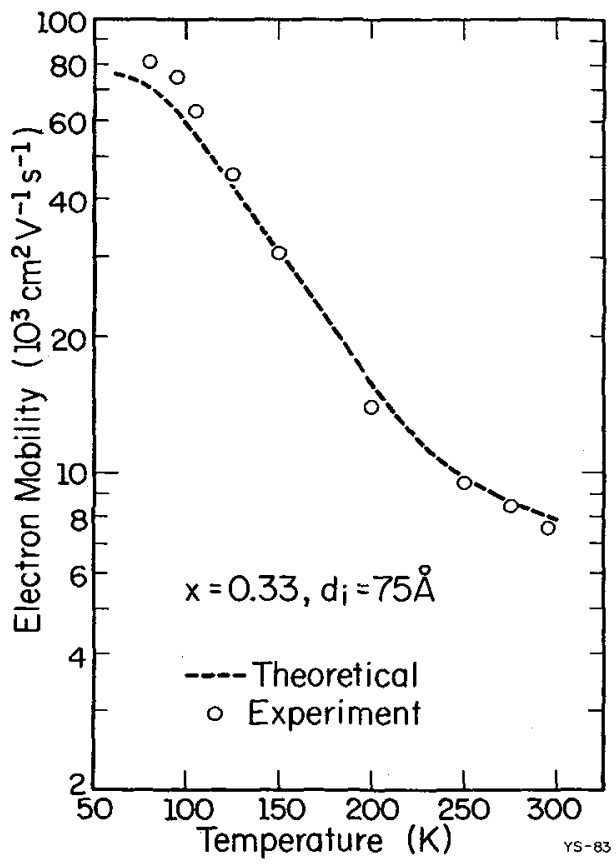

Fig. 2: Comparison of theoretical and experimental values of the mobility of modulation-doped structure plotted vs temperature after Drummond et a1. [13]

An example of the good fit of theory and experimental data is shown in Figure 2 where the mobility of a modulation-doped structure is plotted vs temperature. Note, however, that no satisfactory explanation has been given up to now for 
extremely high mobilities $\left(\gtrsim 2 \times 10^{5} \mathrm{~cm}^{2} / \mathrm{Vs}\right)$ at low temperatures $(10 \mathrm{~K})$ as they are currently reached [14].

\subsection{The Warm Electron Range}

Warm electron effects in bulk GaAs having low electron densities can be described properly only by including the non-Maxwellian (non-Fermi-type) nature of the distribution function. The mobility in bulk GaAs with a high donor concentration (high electron densities) is very low and therefore warm electron effects (below the Gunn threshold) are not usua11y observed. Selectively doped (A1, Ga) As/GaAs heterostructures combine the unique feature of high mobilities associated with large electron concentrations. Warm electron effects in these structures should therefore be treated with a model including strong electron-electron interactions. The simplest way of including electron-electron scattering is the assumption of a Fermi-distribution at elevated electron temperature $T_{c}$ for the spherical symmetrical part of the distribution function.

The calculation is then straightforward using the two-dimensional model for the mobility as described above. To calculate the carrier temperature $T_{C}$ we can $u s e$ the power balance equation as derived before [15]. (At low temperatures we have to include the power loss to acoustic modes [16].) Experimental curves for a very high mobility $\left(\mu \simeq 2 \times 10^{5} \mathrm{~cm}^{2} / \mathrm{Vs}\right.$ at $\left.10 \mathrm{~K}\right)$ modulation doped structures [17] are shown in Figure 3. A theoretical curve is shown for comparison.

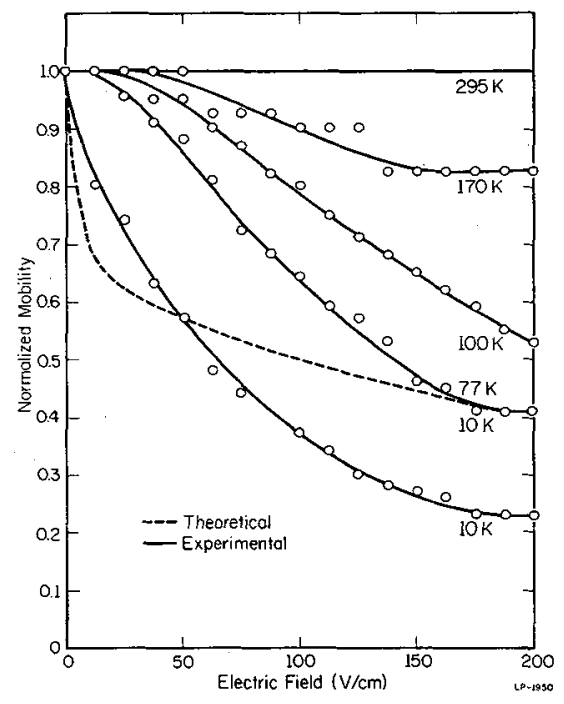

Fig. 3: Experimental (0) and theoretical (--) results for the normalized mobility of modulation-doped structures at moderate electric fields. The full lines are only guides for the eye to the experimental results. After Drummond et a1. [17].

In comparing experimental and theoretical results, two aspects are apparent. At very low fields the theory predicts a deviation from $0 \mathrm{hm}^{\prime} \mathrm{s}$ law, which is steeper than the experimenta1ly observed deviation. This discrepancy can be accounted for 
only by assigning a relatively large energy loss rate to interactions with phonons. In our model a deformation potential of $10 \mathrm{eV}$ which is rather large was assumed. Therefore, an explanation seems to be possible only by additional phonon scattering processes, such as piezoelectric scattering and multiphonon emission.

At higher electric fields, the rate of decline in the electron mobility decreases, which may be an indication of a lower energy loss rate than what was used in our model. This type of deviation between theory and experiment is typical for deviations of the distribution functions from the Fermi-shape, which we have assumed. Around $300 \mathrm{~V} / \mathrm{cm}$ a slight negative differential resistance occurs which could be connected with subband repopulation and the sudden onset of (two-dimensiona1) polar optical scattering [18].

\subsection{The Hot E1ectron Range}

The effects discussed so far are not entirely different from effects observed in MOS-transistors where the electrons also are quasi-two-dimensional. At very high electric fields $(\geqslant 3000 \mathrm{~V} / \mathrm{cm})$, however, new effects occur if the band edge discontinuity $\Delta E_{c}$ is small. Since $\Delta E_{c}$ is a function of the Al content, i.e., of $x$, it can be adjusted by varying $x$. For $x \leqslant 0.23$ the band edge discontinuity $\Delta E_{c}$ is smaller than the energy separation of the satellite minima. In other words, the electrons can move out of the GaAs before the Gunn effect occurs and in this way cause a realspace negative differential resistance if the mobility (at high fields) in the $\mathrm{Al}_{\mathbf{x}} \mathrm{Ga}_{1-\mathrm{x}} \mathrm{As}$ is much lower than the mobility (at high fields) in the GaAs. This requires, of course, heavy doping in the $\mathrm{Al}_{\mathrm{x}} \mathrm{Ga}_{1-\mathrm{x}} \mathrm{As}$. In order to deplete the $\mathrm{Al}_{\mathrm{x}} \mathrm{Ga}{ }_{1-\mathrm{x}} \mathrm{As}$ at low fields completely it may be necessary to compensate the material. In the very first publication on this effect we assumed that a rather wide layer of $\mathrm{Al}_{\mathrm{x}} \mathrm{Ga}{ }_{1-\mathrm{x}} \mathrm{As}$ is necessary for a high peak-to-valley ratio so that the electron really would "get lost" in the poorly conducting $A 1_{x} a_{1-x} A s$. The experiments showed, however, that the actual thickness of the $\mathrm{Al}_{\mathrm{x}} \mathrm{Ga}{ }_{1-\mathrm{x}} \mathrm{As}$ is rather unessential possibly because the positive donors attract the electrons strongly enough to keep them in even small ( $\sim 1500 \AA$ in our experiments) layers provided the electric field is high enough.

The details of the real-space transfer mechanism are fairly complicated and cannot be derived analytically. Nevertheless, one can give explicit descriptions for the most important features. Therefore, I will treat the speed, the critical field, the scattering mechanisms and the transfer itself below and then present the results of Monte Carlo calculations performed by Glisson et al. [5].

To calculate the switching speed we observe that the potential wells in Fig. 1 are similar to the step-like wells in charge coupled devices, where electrons move by diffusion from one gate to another. Using this analogy, we obtain the time $t_{s}$ which the electrons need to fall back to the GaAs layer after switching of the "heating" field [4]:

$$
t_{S} \approx 4 L_{2}^{2} / \pi^{2} D
$$


where $\mathrm{L}_{2}$ is the thickness of the $A I_{x} \mathrm{Ga}_{1-\mathrm{x}} \mathrm{As}$ layer, and $\mathrm{D}$ is the diffusion constant in the $\mathrm{Al}_{\mathrm{x}} \mathrm{Ga} \mathrm{I}_{1-\mathrm{x}} \mathrm{As}$. This formula is valid only as long as the diffusion concept applies and the mean free path for phonon emission $\lambda_{\text {ph }}$ is smaller than $\mathrm{L}_{1}$, the thickness of the GaAs layer. If $\lambda_{\mathrm{ph}}$ is longer than $\mathrm{L}_{1}$, the probability of an electron being captured in the well is reduced by $\mathrm{L}_{1} / \lambda_{\mathrm{ph}}$. Thus we have

$$
\mathrm{t}_{\mathrm{s}} \approx 4 \mathrm{~L}_{2}^{2} \lambda_{\mathrm{ph}} / \pi^{2} \mathrm{DL}_{1}
$$

For typical values such as $\mathrm{L}_{1}=\mathrm{L}_{2}=400 \AA, \lambda_{\mathrm{ph}}<10^{-5} \mathrm{~cm}$, and $\mathrm{D}=1 \mathrm{~cm}^{2} / \mathrm{s}$, we obtain $t_{s}<1.62 \times 10^{-11} \mathrm{~s}$, which is an attractively short time for a variety of applications. Of course, one must add the time required for heating and cooling of the electrons, about $5 \times 10^{-12} \mathrm{~s}$, to $t_{s^{*}}$ In deriving Eq. (6), it was assumed that there is no potential barrier caused by the ionized donors in the $\mathrm{Al}_{\mathrm{x}} \mathrm{Ga}_{1-\mathrm{x}} \mathrm{As}$. The potential barrier created by such donors is comparable to $\mathrm{kT}_{\mathrm{L}} / \mathrm{e}$ for an $\mathrm{Al}_{\mathrm{x}} \mathrm{Ga}_{1-\mathrm{x}} \mathrm{As}$ layer width of $600 \AA$, a net donor doping concentration of $10^{16} \mathrm{~cm}^{-3}$, and $\mathrm{T}_{\mathrm{L}}=300 \mathrm{~K}$. of course, the continuum approximation is poor and the $\mathrm{Al}_{\mathrm{x}} \mathrm{Ga}_{1-\mathrm{x}} \mathrm{As}$ has to be strongly compensated to achieve low mobility.

If the layers are very thin and the potential barrier created by the donors is high, the diffusion concept breaks down and the back transfer will be "thermionic emission" limited. The principles of the thermionic emission current are wel1 known and we can immediately obtain the back-transfer time [4]:

$$
t_{s} \approx \frac{{ }^{e N}{ }_{c}{ }_{2}{ }^{m}}{{ }_{A T_{L}}^{2}{ }^{*}} \exp \left(\frac{e \phi}{{ }_{k T}}\right)
$$

where $A$ is the Richardson constant, $\mathrm{m}^{*}$ is the effective mass, $\mathrm{m}_{0}$ is the free-electtron mass, $\phi$ is the potential created by the donors in the $\mathrm{Al}_{\mathrm{x}} \mathrm{Ga}{ }_{1-\mathrm{x}} \mathrm{As}$, and $\mathrm{N}_{c}$ is the density of states in $\mathrm{Al}_{\mathrm{x}} \mathrm{Ga}{ }_{1-\mathrm{x}} \mathrm{As}$. For $e \phi / \mathrm{kT}_{\mathrm{L}} \lesssim 2, \mathrm{t}_{\mathrm{s}}$ is about $10^{-12} \mathrm{~s}$, and therefore the transfer speed is also determined by the heating and cooling time and the time needed to replenish electrons with high enough kinetic energy to overcome the barrier. Both time constants are determined by collision rates and are about $5 \times 10^{-12} \mathrm{~s}$. A correction factor of $\mathrm{L}_{1} / \lambda_{\mathrm{ph}}$ must be introduced for $\lambda_{\mathrm{ph}}>\mathrm{L}_{1}$.

The transfer out of the GaAs is also dominated by the time constant in Eq. (7). We only have to replace $\phi$ by the band edge discontinuity and the lattice temperature $T_{L}$ by the actual temperature of the carriers $T_{c}$ which is much larger than $T_{L}$ in $h f_{g h}$ fields. Even if $T_{c}$ can be defined (high electron-electron scattering rate) the actual calculation is still not straightforward because of the presence of the interface and electronic heat conduction effects [6]. Also, we have to account for the two-dimensional nature of the electrons at low fields. Roughly speaking, however, we can expect that $T_{c}$ is high enough for the transfer at about the same (or a little smaller) critical field which causes the Gunn effect, since polar optical scattering exhibits a steep increase of $\mathrm{T}_{\mathrm{c}}$ at this field (a slightly higher 
field for two-dimensional systems [12]). We are now left with the description of the transfer mechanism itself. In a single-layer structure we have to calculate the quantum mechanical transmission coefficient [19] which is zero if the electron energy is below $\Delta \mathrm{E}_{\mathrm{c}}$ and approaches one at energies substantially higher than $\Delta \mathrm{E}_{\mathrm{c}}$. At $1.25 \Delta \mathrm{E}_{c}$ it is about 0.6 [19] if the Bloch-nature of the wave function is taken into account. In a superlattice the electron does not need to reach $\Delta \mathrm{E}_{c}$ to propagate; it needs only be excited to the conduction band among the minibands. A Monte Carlo simulation which includes most of the effects discussed above (except the twodimensional effects [20]) was performed and the resulting current-voltage characterization is shown in Fig. 4, which also shows the real space trajectory of an electron in the inset. The figure shows clearly that the curves can be tailored by the doping concentration substantially. Details about the dependences on $x, \Delta E_{c}$, etc. can be found in ref. [5].

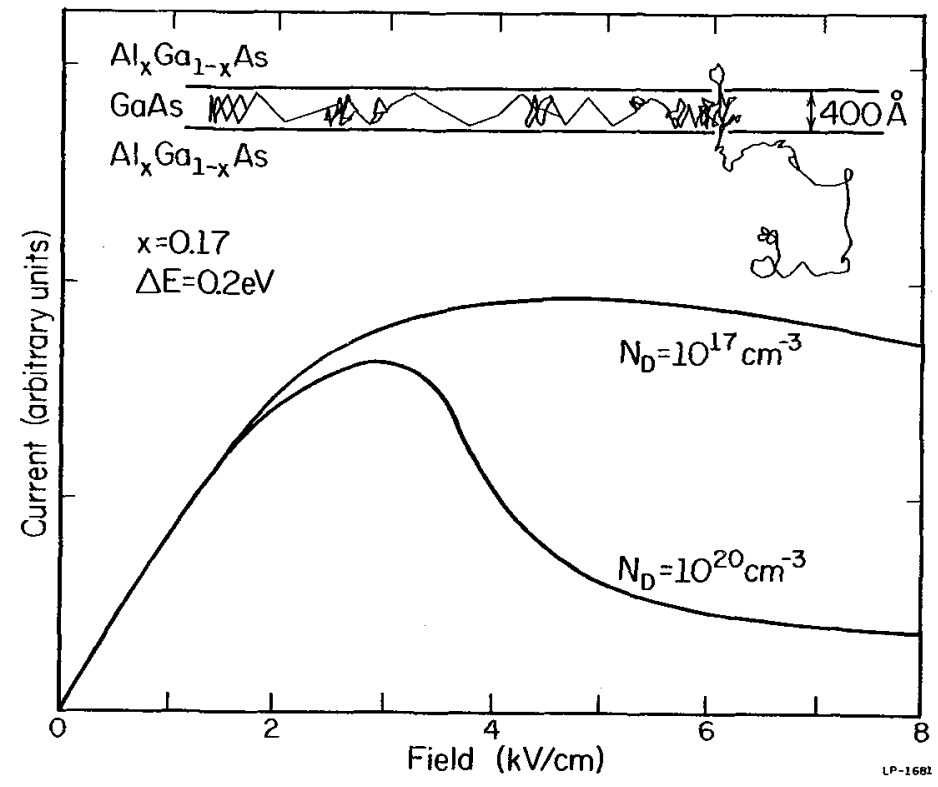

Fig. 4: Current-field characteristics for the double-heterojunction structure shown in the inset with $\mathrm{AI}_{3} \mathrm{xa}_{1-\mathrm{x}} \mathrm{As}$ densities of $10^{17} \mathrm{~cm}^{-3}(\mu=4000 \mathrm{~cm} / \mathrm{Vs})$ and $10^{20} \mathrm{~cm}^{-3^{x}}\left(\mu=50 \mathrm{~cm}^{2} / \mathrm{Vs}\right)$. The thickness of the AlGaAs layer is $4000 \AA$ and the GaAs is $400 \AA$ thick and has $\mu=8000 \mathrm{~cm}^{2} / \mathrm{Vs}$ in both cases. The inset shows a Monte Carlo simulation of the path of an electron when a high electric field is applied parallel to the layer interfaces.

I have described the negative differential resistance by real-space transfer in greater detail because it has meanwhile been verified experimenta11y. Actually the effect is only one of many effects which can be derived from $\vec{k}-s p a c e-r e a l-s p a c e$ analogies. The intervalley noise in Gunn devices has a real space analogy which 
can be important in charge coupled devices [21]. The intervalley diffusion (spread of charge packet because of different effective masses in different valleys) has a real-space analogy in superlattices at very high fields (spread of charge packet because of different mobilities in different layers). There is also a real-space analogy to the sp1it band impact ionization resonance which I would 1ike to out1ine in more detail because of its possible device application.

The signal/noise ratio of avalanche photodiodes (APD) is influenced significantly by the statistics of the gain process and because of feedback effects more noise is generated when both electrons and holes produce secondary pairs. The lowest excess noise is achieved in APDs if the ratio of the electron ionization rate $(\alpha)$ to the ionization rate of holes $(B)$ is either infinite (electron multiplication only) or zero (hole multiplication only). A possibility of achieving this is offered by the specific band structure of $\mathrm{Ga}_{\mathrm{x}} \mathrm{Al}_{1-\mathrm{x}} \mathrm{Sb}$.

In this material it happens at a certain composition that the split off valence band is separated from the top of the valence band just by the amount of the energy gap. Therefore holes at the maximum of the splitband are able to impact ionize. In sufficiently high electric fields holes will populate the splitband because of interband phonon scattering. The electrons which are able to impact ionize, however, do not have any states near $k=0$ and therefore need a much higher energy to impact ionize than the holes as dictated by both the conservation of energy and momentum. The real-space analogy to this effect is caused by the asymmetric band edge discontinuity for electrons $\Delta E_{c}$ and for holes $\Delta E_{v}$. Consider an electron at an energy of $1.5 \mathrm{eV}$ in AlAs electrons transferring to GaAs in a layered structure. As soon as the electron has transferred it finds itself $\sim 2.3 \mathrm{eV}$ above the GaAs conduction band edge and can therefore impact ionize (the threshold is around $2 \mathrm{eV}$ ) while a hole with similar history would be on $1 \mathrm{y} \sim 1.65 \mathrm{eV}$ below the top of the GaAs valence band and could not contribute to impact ionization. Device structures to exploit this effect have been proposed [22].

Let me finally emphasize that the variety of achievable effects by real-space transfer can be substantially increased if the layers can be heated separately [3] . Switching and storage between the layers with time constants reaching from hours to $10^{-11} \mathrm{sec}$ should be possible (see Eq. (7)). This makes the effect attractive for digital applications.

\section{Experimenta1 Results}

Some experimental results for the ohmic and for the warm electron range have already been presented in the previous chapter. More detailed accounts can be found in refs. $[13,17]$.

Results for the hot electron range are show in Fig. 5. These results are representative for measurements on many wafers of different geometry and doping profiles. The material parameters and dimensions of the samples which were prepared by kolecular Beam Epitaxy are as follows. The doping density in the 


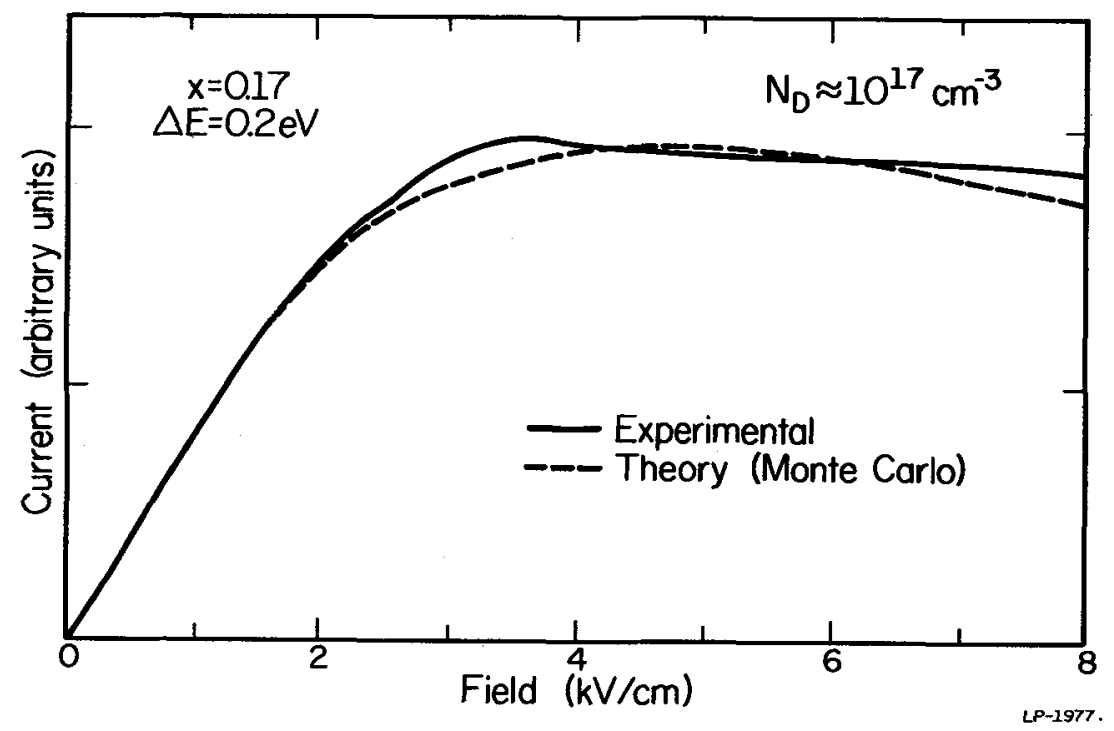

Fig. 5: Experimental and theoretical results for the current-voltage characteristics of a modulation doped $\left(N_{D} \simeq 10^{17} \mathrm{~cm}^{-3}\right.$ in the

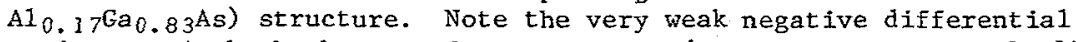
resistance in both theory and experiment. (After Keever et a1. [23])

$\mathrm{A} 1_{\mathrm{X}} \mathrm{Ga}{ }_{1-\mathrm{X}}$ As layers was $\mathrm{N}_{\mathrm{D}} \approx 10^{17} \mathrm{~cm}^{-3}$ and the GaAs was not intentional1y doped. The mobility in the GaAs layers was enhanced over the bulk value for equivalent doping and was typically $2 \times 10^{4} \mathrm{~cm}^{2} / \mathrm{Vs}$ at $77 \mathrm{~K}$. The mobility in the $\mathrm{AI}_{\mathrm{x}} \mathrm{Ga}_{1-\mathrm{x}}$ As layers was around $1000 \mathrm{~cm}^{2} / \mathrm{Vs}$ between 300 and $77 \mathrm{~K}$. The doped $\mathrm{A} 1_{\mathrm{x}} \mathrm{Ga}_{1-\mathrm{x}}$ As layer was $1000 \AA$ thick in all cases, whereas the GaAs layers varied in thickness from $400 \AA$ to $\sim 1.0 \mu \mathrm{m}$. In some of the samples the GaAs layer was sandwiched between the doped and a second (undoped) $\mathrm{Al}_{\mathrm{X}} \mathrm{Ga}_{1-\mathrm{x}}$ As layer. As mentioned before, we think that the actual width of the GaAs layer is relatively unimportant because of the pulling force of the donors, since the electrons in the GaAs will always be within $1000 \AA$ of the doped $\mathrm{Al} \mathrm{x}_{\mathrm{Ga}}{ }_{1-\mathrm{x}}$ As layer. Although $\mathrm{x}$ was 0.17 for most of the data reported here, we have made similar measurements with $x$ increased to 0.25 . Au-Ge contacts were evaporated on top of the layer (top layer $\mathrm{Al}_{\mathrm{x}} \mathrm{Ga}_{1-\mathrm{x}} \mathrm{As}$ ) and alloyed by heating at a rate of $400^{\circ} \mathrm{C} / \mathrm{min}$ in flowing $\mathrm{H}_{2}$ to a fina1 temperature of $450^{\circ} \mathrm{C}$. Contacts formed in this way proved to be ohmic in most cases.

The distance between the contacts was $0.065 \mathrm{~cm}$ and the width of the samples was $0.1 \mathrm{~cm}$. Recently we have also used very different geometries. Samples with a contact distance of $\sim 0.01 \mathrm{~cm}$ and a width of $0.1 \mathrm{~cm}$ and also samples in with the inverse length to width ratio did not show significantly different effects. The 
measurements have been performed using standard short current pulse techniques [23] . In all samples used up to now we have not observed Gunn oscillations. The reason for this is not entirely understood. However, we can point out the following distinct differences between real-space transfer and the RWH mechanism. There is no local microscopic negative differential resistance in the $\mathrm{Al}_{\mathrm{X}} \mathrm{Ga}_{1-\mathrm{X}} \mathrm{As}$ at the electric fields considered. Accumulation (and therefore dipole) domains cannot be formed because accumulating electrons would be emitted out of the GaAs. The total lack of any kind of instability, however, does not necessarily follow from these arguments and might be connected with fixed interface inhomogeneities at which the electrons spill out first and with the fact that the layers are extremely thin and the sensitivity of the Gunn instability to the dimensionality [24]. Fig. 6 shows results obtained for samples which were made with a single layer of doped $\mathrm{Al}_{\mathrm{x}} \mathrm{Ga}_{1-\mathrm{x}} \mathrm{As}$ on top

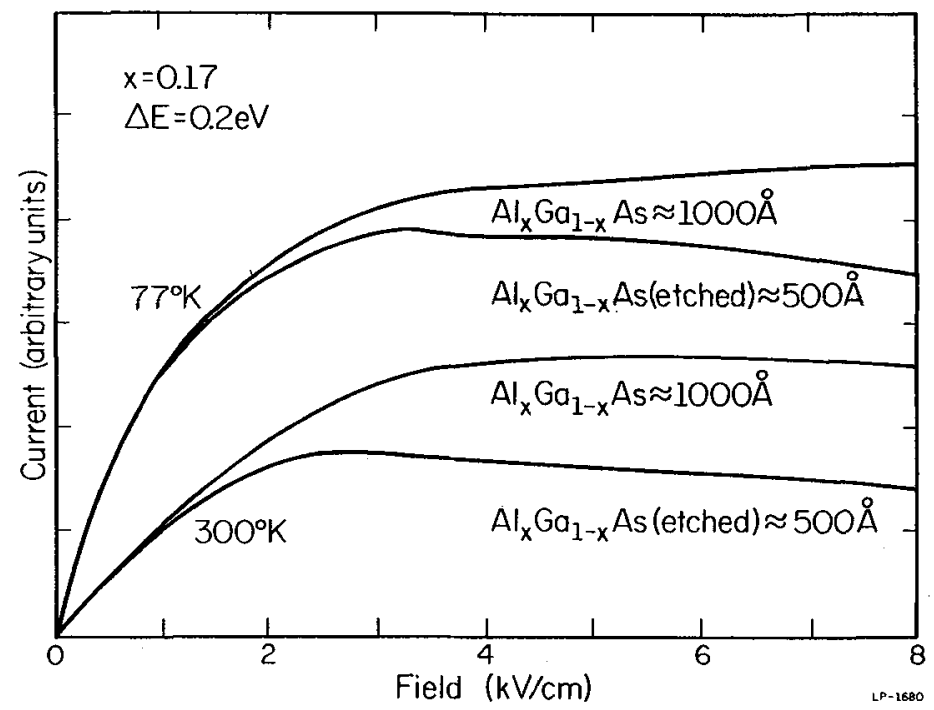

Fig. 6: Current voltage characteristic of modulation doped structure before and after changing the surface conditions and layer width by etching.

of not intentionally doped GaAs. The surface conditions and the $\mathrm{Al}_{\mathrm{x}} \mathrm{Ga}_{1-\mathrm{x}} \mathrm{As}$ thickness was changed in these samples by subsequent etching. It was observed that the Ohmic conductivity hardly changed while drastic changes appeared in the high field conductance. This is a very strong argument for the actual transfer of the electrons into the $\mathrm{Al}_{\mathrm{x}} \mathrm{Ga}_{1-\mathrm{x}} \mathrm{As}$. Generally, the variety of changes of the current-voltage characteristic which is observed in samples with different doping makes it appear that new effects occur in these structures and that the negative differential resistances and current saturations observed are not merely caused by the Gunn effect in the GaAs layer. A more direct proof of the real space transfer effect can 
possibly be achieved by picosecond spectroscopy and/or time of flight measurements.

In the experiments described above inhomogeneities of the electric field will mask the true microscopic characteristic in the range of negative differential resistance. Estimates of this effect are difficult because the continuum approximation for the impurity charge and the band bending is not good. (The spacing of the impurities is of the order of the layer width.) The form of the current voltage characteristic also depends sensitively on whether free charge carriers are left in in the $\mathrm{Al}_{\mathrm{x}} \mathrm{Ga}{ }_{1-\mathrm{x}} \mathrm{As}$ or if the $\mathrm{A} \mathrm{I}_{\mathrm{x}} \mathrm{Ga}_{1-\mathrm{x}} \mathrm{As}$ is entirely depleted. This is shown in Fig. 7. The curve which shows the saturation was measured on a sample which had no or very few electrons in the $\mathrm{Al}_{\mathrm{x}} \mathrm{Ga}{ }_{1-\mathrm{x}} \mathrm{As}$ while the second curve (aImost ohmic) was

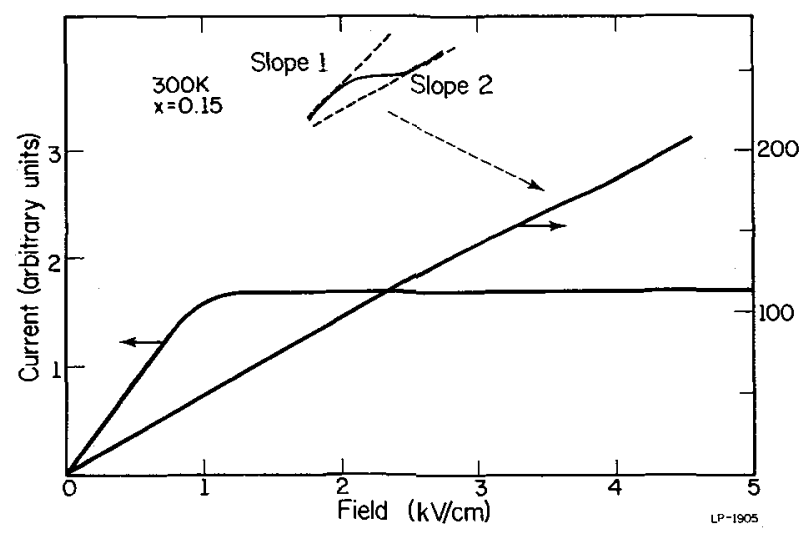

Fig. 7: Current voltage characteristic of modulationdoped structure under different conditions of

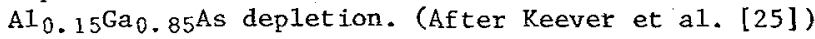

taken from a sample with electrons left in the $\mathrm{Al} \mathrm{X}_{\mathrm{X}} \mathrm{Ga}_{1-\mathrm{X}} \mathrm{As}$ layer. In this case the only appearance of the real space transfer is given by the slight change in slope at high electric fields (see inset of Fig, 7). In a few samples we have observed a negative differential resistance with extremely high peak-to-valley ratio. In these samples the mobility in the $\mathrm{Al}_{\mathrm{x}} \mathrm{Ga}_{1-\mathrm{x}} \mathrm{As}$ was probably very low while the GaAs mobility was still very high. A representative result is given in Fig. 8 . More detailed discussions of some of the effects mentioned can be found in refs. $[23,25]$. 


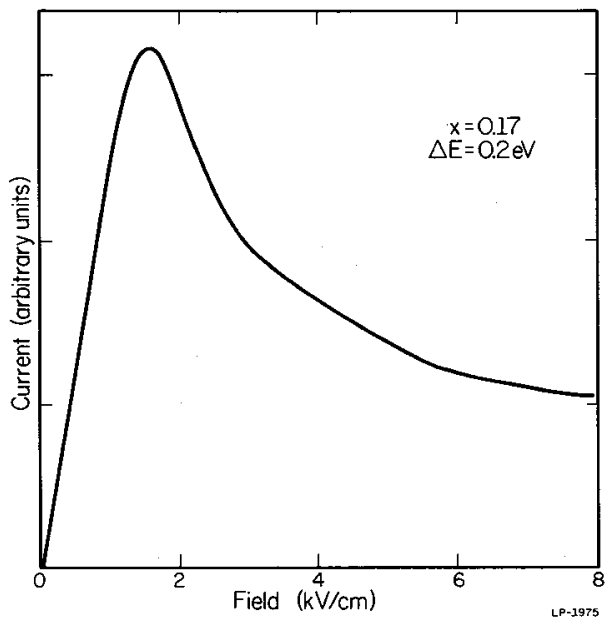

Fig. 8: Experimental currentvoltage characteristic of modulation-doped structure with extremely high peak- tovalley ratio. Only two samples exhibited such large effects possibly because of a very low mobility in the $\mathrm{Al}_{0.17} \mathrm{Ga}_{0.83} \mathrm{As}$ (high compensation).

\section{Conclusions}

It has been shown that lateral transport in superlattices offers new features in the Ohmic range, the warm electron range, and especially at high electric fields when the average energy of the electron is comparable to the band edge discontinuity. In the Ohmic range, high mobilities can be achieved by modulation doping. The effects are especially dramatic at low temperatures. In the range of warm electrons, stronger deviations from $\mathrm{Ohm}$ 's law occur as compared to bulk material. Also the electron densities are extremely high, making the electron-electron interaction important. In the hot electron range the electrons leave their host layer (GaAs) and reunite either with their parent donors or populate a neighboring cold layer (if no electric field is applied to this layer) which acts as a single giant electron trap [3]. The switching and back-transfer time constants depend exponentially on the composition $x$ and on the doping, as can be seen from Eq. (7). Therefore, time constants ranging from $10^{-12} \mathrm{sec}$ to many seconds and even years (at low temperatures) can be adjusted at will. The effect should be attractive for switching applications of various kinds. Furthermore, I have shown that a general correspondence exists between transport effects in $\vec{k}$-space and real-space. We have demonstrated the use of this correspondence in problems of noise [21] and impact ionization [22] etc., in addition to the use for Gunn-like real-space transfer devices and switching applications. All these effects are consequences of the complicated boundary conditions imposed (be they periodic or not). It is exactly the large variability of the boundary conditions which make layered heterojunction structures so attractive for transport as described here as well as for optoelectronics $[26]$. 
Acknowledgements. - It is a pleasure to thank my colleagues N. Holonyak, Jr., H. Morkoc, G. E. Stillman, and B. G. Streetman for many valuable discussions. The work was supported by the Office of Naval Research, the Army Research Office, and the Joint Services Electronics Program.

\section{References}

1. C. Hilsum, Solid State Electronics 21 , 5 (1978).

2. "Experience and history teach that people and governments never have learnt anything from history."

3. K. Hess, B. G. Streetman, and H. Morkoc, "Negative resistance heterojunction devices," U. S. Patent No. 4,257,055, March 17, 1981.

4. K. Hess, H. Morkoc, H. Shichijo, and B. G. Streetman, App1. Phys. Lett. $\underline{35}$, 469 (1979).

5. T. H. Glisson, J. R. Hauser, M. A. Littlejohn, K. Hess, B. G. Streetman, and H. Shichijo, J. App1. Phys. 51, 5445 (1980).

6. H. Shichijo, K. Hess, and B. G. Streetman, Solid State Electronics 23, 817 (1980).

7. T. Ning, Solid-State Electron. 21, 273 (1978).

8. A. Dargis, S. Zhilyonis, A. Matulionis, I. Parshelyumas, Yuris K. Pozhela, A. Poshkus, E. Shimulitye, Lietuvos Fizikos Rinkinys 17, Nos. 3 and 4 (1977), Vilnius (in Russian).

9. The effect was proposed by L. Esaki and R. Tsu, IBM Research Report No. RC-2418 (1969) and found experimenta1ly by R. Dingle, H. L. StOrmer, A. C. Gossard, W. Wiegmann, App1- Phys. Lett. $\underline{3}, 665$ (1978).

10. L. Esaki and R. Tsu, IBM J. Res. Develop. 14, 61 (1970).

11. P. J. Price, J. Vac. Sci. and Technol., to be published and Annals of Physics, to be published.

12. K. Hess, App1. Phys. Lett. $\underline{35}, 484$ (1979).

13. T. J. Drunmond, H. Morkoc, K. Hess, and A. Y. Cho, J. App1. Phys., to be published.

14. Hadis Morkoc, private communication.

15. K. Hess, N. Holonyak, Jr., W. D. Laidig, B. A. Vojak, J. J. Coleman, and P. D. Dapkus, Solid State Communications 34, 749 (1980).

16. K. Hess, So1id State Communications 25, 191 (1978).

17. T. J. Drummond, M. Keever, W. Kopp, H. Morkos, K. Hess, A. Y. Cho, and B. G. Streetman, Electronics Letters, to be published.

18. M. Keever, H. Morkoc, T. J. Drummond and K. Hess, to be published.

19. G. C. Osbourn and D. L. Smith, Phys. Rev. B 19, 2124 (1979).

20. Two-dimensional effects have been treated by H. Shichijo, Theoretical Studies of High Field Transport in III-V Semiconductors, Ph.D. Thesis, University of Illinois, Coordinated Science Laboratory Report No. R-893 (1980).

21. J. Y. Tang and K. Hess, IEEE Transactions on Electron Devices ED28, 285 (1981).

22. R. Chin, N. Holonyak, Jr., G. E. Stillman, J. Y. Tang, and K. Hess, Electronics Letters $\underline{16}, 467$ (1980).

23. M. Keever, H. Shichijo, K. Hess, S. Banerjee, L. Witkowski, H. Morkoc, and B.

G. Streetman, Appl. Phys. Lett. 38,36 (1981).

24. H. Kroemer, private communication. 
25. M. Keever, T. Drummond, H. Morkoç, K. Hess, B. G. Streetman, and M. Ludowise, J. Appl. Phys., to be published.

26. K. Hess and N. Holonyak, Jr., Physics Today, October (1980). 